\title{
Evaluation of Calprotectin Levels in First-Degree Relatives of Patients with Ulcerative Colitis
}

\author{
Solmaz Razi ${ }^{1}$, Katayoon Ghasemi ${ }^{1}$, Mohsen Masoodi ${ }^{2, *}$ \\ ${ }^{1}$ Department of Internal Medicine, School of Medicine, Iran University of Medical Sciences, Tehran, Iran \\ ${ }^{2}$ Colorectal Research Center, Iran University of Medical Sciences, Tehran, Iran

\section{Email address:} \\ solmazrazi@yahoo.com (S. Razi),k.ghasemi63@gmail.com (K. Ghasemi), Masoodi47@yahoo.com (M. Masoodi), \\ Masoodi.m@iums.ac.ir (M. Masoodi) \\ ${ }^{*}$ Corresponding author
}

\section{To cite this article:}

Solmaz Razi, Katayoon Ghasemi, Mohsen Masoodi. Evaluation of Calprotectin Levels in First-Degree Relatives of Patients with Ulcerative Colitis. International Journal of Biomedical Engineering and Clinical Science. Vol. 7, No. 3, 2021, pp. 48-51.

doi: 10.11648/j.ijbecs.20210703.12

Received: June 18, 2021; Accepted: July 13, 2021; Published: August 23, 2021

\begin{abstract}
Recent studies have shown the diagnostic value of fecal as well as serum calprotectin in predicting the severity and activity of inflammatory bowel disease. Given the strong familial and inherited predisposition to inflammatory bowel disease, it is assumed that changes in calprotectin levels are also influenced by familial predispositions. Therefore, the present study aimed to evaluate the level of fecal calprotectin in patients and their first-degree relatives in order to determine the relationship between changes in this marker and its possible familial orientation. The study participants were the first-degree relatives $(\mathrm{n}=100)$ of the patients $(\mathrm{n}=33)$ with the definitive diagnosis of ulcerative colitis who referred to Rasoul-e-Akram hospital in 2018 and 2019. The fecal value of calprotectin was assessed using the ELISA method in both patients and the relatives. Fecal calprotectin level in patients was estimated to be $232.09 \pm 44.16 \mu \mathrm{g} / \mathrm{g}$. Fecal calprotectin level in the parents was $86.06 \pm 12.66 \mu \mathrm{g} / \mathrm{g}$, in siblings was $58.02 \pm 7.24 \mu \mathrm{g} / \mathrm{g}$ and in the patient's children was $47.40 \pm 4.77 \mu \mathrm{g} / \mathrm{g}$. Fecal calprotectin levels were not affected by baseline indices such as gender, age, or BMI (either in patients or their relatives) and therefore these baseline factors had no effect on fecal calprotectin levels. Although fecal calprotectin levels are significantly longer in patients with ulcerative colitis than in healthy controls, the higher level of this marker among first-degree relatives of patients than healthy individuals also indicates the inherited tendency of changes in this marker in terms of high risk of disease in firstdegree relatives of patients. These changes in fecal calprotectin levels will be independent of gender, age, and BMI
\end{abstract}

Keywords: Evaluation, Calprotectin Levels, Ulcerative Colitis

\section{Introduction}

Ulcerative colitis is a type of inflammatory bowel disease that has a prevalence of 63.6 per 100,000 people and is usually mild to moderate in more than $80 \%$ of patients [1]. The incidence of this disease is about 6 per 100,000 people [2], which varies in different geographical areas. About 1.4 million people in the United States and 2.2 million in Europe suffer from this disease, and various risk factors such as smoking and appendectomy have been suggested as factors that increase the risk of ulcerative colitis [3]. Of course, it should be noted that the risk factors for ulcerative colitis in Iran are similar to those risk factors that have already been reported in other countries [4]. Ulcerative colitis is mostly mild; but in severe cases, it can cause stress and anxiety [5]. This is so important that in some areas, despite treatment, $17 \%$ of patients with severe disease die [6] shows the importance of determining the severity of the disease in order to carry out proper treatment planning so that we can reduce morbidity and mortality and the overall burden of the disease. The most important issue in patients with this disease is the severity of gastrointestinal inflammation due to the recurrence and remission periods of the disease, and in this regard, some leukocyte markers such as calprotectin released by neutrophils in the gastrointestinal tract, both in the blood and feces are helpful [7]. Calprotectin is a calcium binding protein that is found mainly in neutrophils and to a lesser extent in monocytes and reactive macrophages [8]. It belongs to a subgroup of proteins that is associated with acute/chronic 
inflammatory disorders and a number of malignancies $[8,9]$.

This inflammatory marker can be used as a non-invasive measurable indicator of gastrointestinal inflammation in patients with ulcerative colitis, and at the same time it can be used to monitor the therapeutic results and follow-up of patients. In this regard, the sensitivity of this marker ranged between 94 and 100\% based on the underlying conditions of the patients [10-12]. Due to the genetic characteristics of ulcerative colitis, there is a possibility of involvement in firstdegree relatives of these patients [13] and thus the earlier diagnosis of disease in relatives, the better prognosis of disease in the relatives of the patients can be expected. Additionally, Due to its non-invasiveness and high sensitivity of calprotectin, this marker can be a good candidate for screening in close asymptomatic relatives of patients with ulcerative colitis. Accordingly, and considering the importance of the matter, in this study we decided to investigate the level of calprotectin in first-degree relatives of patients with ulcerative colitis.

\section{Materials and Methods}

In this descriptive cross-sectional study, the aim was to evaluate the level of calprotectin in first-degree relatives of patients with ulcerative colitis. The study participants were the first-degree relatives of the patients with the definitive diagnosis of ulcerative colitis who referred to Rasoul-eAkram hospital in 2018 and 2019. Exclusion criterion was individuals' dissatisfaction with sampling for calprotectin or history of inflammatory disorders or using anticoagulants. The baseline characteristics including demographics (gender and age) were medical history were collected by interviewing the patients and their relatives. The body mass index was determined by weight in kilograms divided by the square of the height in meters. The fecal value of calprotectin was assessed using the ELISA method in both patients and the relatives.

Descriptive analysis was used to describe the data, including mean \pm standard deviation (SD) for quantitative variables and frequency (percentage) for categorical variables Chi square test, independent $t$ test and Mann-Whitney $U$ test were used for comparison of variables. The association between the quantitative indices was tested by the Pearson's or Spearman's test. For the statistical analysis, the statistical software IBM SPSS Statistics for Windows version 22.0 (IBM Corp. Released 2013, Armonk, New York) was used. P values $<0.05$ were considered statistically significant.

\section{Results}

In the present study, a total of 33 patients with ulcerative colitis and 100 relatives of their degree were included in the study. The mean age of men and women was $42.84 \pm 16.77$ years and $40.46 \pm 13.97$ years, respectively with no significant difference $(\mathrm{p}=$ 0.40 ). The mean age of parents, siblings and children was $56.38 \pm 13.47$ years, $35.52 \pm 5.75$ years and $27.48 \pm 4.99$ years, respectively. Also, the mean BMI in men and women was
$25.89 \pm 2.58 \mathrm{~kg} / \mathrm{m}^{2}$ and $27.07 \pm 2.61 \mathrm{~kg} / \mathrm{m}^{2}$, respectively, which was significantly higher in women $(\mathrm{P}=0.027)$.

The mean level of fecal calprotectin concentration in patients was $232.09 \pm 44.16 \mu \mathrm{g} / \mathrm{g}$. Also, fecal calprotectin levels in male and female patients were $236.00 \pm 46.35 \mu \mathrm{g} / \mathrm{g}$ and $228.18 \pm 41.95 \mu \mathrm{g} / \mathrm{g}$, respectively, which showed no difference between the two sexes $(\mathrm{P}=0.378)$. As shown in Table 1, the level of fecal calprotectin was independent to baseline parameters of gender, age, and BMI of patients. There was no significant correlation of patients' fecal calprotectin levels with baseline variables including age $(\mathrm{r}=$ $0.004, \mathrm{P}=0.969)$ and BMI $(\mathrm{r}=-0.071, \mathrm{P}=0.485)$. The mean level of fecal calprotectin concentration in patients was significantly higher than their parents' fecal calprotectin $(232.09 \pm 44.16 \mu \mathrm{g} / \mathrm{g}$ and $86.06 \pm 12.66 \mu \mathrm{g} / \mathrm{g}, \mathrm{P}<0.001)$. The mean level of fecal calprotectin in patients' relatives was estimated to be $63.8 \pm 18.57 \mu \mathrm{g} / \mathrm{g}$. The mean level of fecal calprotectin in patients was significantly higher than in their brothers and sisters $(232.9 \pm 44.16 \mu \mathrm{g} / \mathrm{g}$ versus $58.02 \pm 7.24$ $\mu \mathrm{g} / \mathrm{g}, \mathrm{p}<0.001)$. The mean level of fecal calprotectin in patients was also significantly higher than in their children $(232.9 \pm 44.16 \mu \mathrm{g} / \mathrm{g}$ and $47.40 \pm 4.77 \mu \mathrm{g} / \mathrm{g}$, respectively, $\mathrm{P}<$ 0.001). Based on Tokay analysis of ANOVA test, fecal calprotectin levels were higher in patients than parents, and in parents high than siblings and children of patients studied. As shown in Table 2, in parents, siblings, and offspring, the value of calprotectin did not depend to their age and BMI.

Table 1. Fecal calprotectin levels in patients based on underlying characteristics.

\begin{tabular}{lll}
\hline Characteristics & Fecal calprotectin level $(\boldsymbol{\mu g} / \mathbf{g})$ & P value \\
\hline Total & $232.09 \pm 44.16$ & \\
Gender & & 0.378 \\
Male & $236.00 \pm 46.35$ & \\
Female & $228.18 \pm 41.95$ & \\
Age & & 0.701 \\
$<40$ years & $233.64 \pm 44.57$ & \\
$>40$ year & $230.21 \pm 44.08$ & 0.257 \\
Body mass index, $\mathrm{kg} / \mathrm{m}^{2}$ & & \\
$<25 \mathrm{~kg} / \mathrm{m}^{2}$ & $239.43 \pm 36.37$ & \\
$>25 \mathrm{~kg} / \mathrm{m}^{2}$ & $228.64 \pm 47.24$ & \\
\hline
\end{tabular}

Table 2. Fecal calprotectin levels in patients based on underlying characteristics.

\begin{tabular}{lll}
\hline Relative & R coefficient & P value \\
\hline Parents & & \\
Age & -0.005 & 0.950 \\
Body mass index & -0.146 & 0.148 \\
Siblings & & \\
Age & 0.172 & 0.088 \\
Body mass index & 0.184 & 0.066 \\
Offspring & & \\
Age & -0.189 & 0.144 \\
Body mass index & -0.091 & 0.389 \\
\hline
\end{tabular}

\section{Discussion}

Recent studies have shown the diagnostic value of fecal and serum calprotectin levels in predicting the severity and activity of inflammatory bowel disease, and in this regard, 
even the diagnostic value of this marker has exceeded other inflammatory indicators associated with the disease. Given the strong familial and inherited predisposition to inflammatory bowel disease, it is assumed that changes in calprotectin levels are also influenced by familial predispositions. Therefore, the present study aimed to evaluate the level of fecal calprotectin in patients and their first-degree relatives in order to determine the relationship between changes in this marker and its possible familial orientation. In the present study, firstly, the level of fecal calprotectin in patients was estimated to be $232.09 \pm 44.16$ $\mu \mathrm{g} / \mathrm{g}$, which was completely consistent with few similar studies in this regard. In a study by Montalto et al [14], the level of fecal calprotectin in patients with ulcerative colitis was estimated to be about $256 \mu \mathrm{g} / \mathrm{g}$, which was consistent with our study. In the study of Thjodleifsson et al [15], the level of fecal calprotectin in patients with Crohn's disease was $47 \mathrm{mg} / \mathrm{l}$, which will be about $240 \mu \mathrm{g} / \mathrm{g}$ with the conversion of the corresponding unit, which was again in the range of the number obtained in our study. But in some studies, in other societies, the number obtained was far beyond our scope. In the study of Xiang et al [16], the level of fecal calprotectin in patients with active ulcerative colitis was estimated to be $402.16 \mu \mathrm{g} / \mathrm{g}$. But what can be seen in almost all studies is a significant increase in fecal calprotectin levels in patients with IBD compared to healthy controls.

As the second finding of the study; the increase in fecal calprotectin level in patients with ulcerative colitis in firstdegree relatives of patients was also beyond normal, but still had a significant distance from the level of this marker in patients. In this regard, the level of fecal calprotectin in the patient's parents was $86.06 \pm 12.66$, in siblings was $58.02 \pm 7.24 \mu \mathrm{g} / \mathrm{g}$, in the patient's children was $47.40 \pm 4.77$ $\mu \mathrm{g} / \mathrm{g}$ and in the patient's spouse was $50.32 \pm 47 / 37 \mu \mathrm{g} / \mathrm{g}$. In this regard, it is necessary to mention a few important points. First, the trend of changes in fecal calprotectin levels in firstdegree relatives (a decreasing trend in order to reduce the relationship with the patient) can indicate a significant relationship between increasing fecal calprotectin levels and its familial tendency. In other words, it can be expected that the level of fecal calprotectin in the patient's parents will be much higher than the patient's spouse, which is the same result. Secondly, in the present study, due to ethical considerations, it was not possible to sample healthy controls, but compared to the results of previous studies, the level of fecal calprotectin in the relatives of our patients was higher than the normal level of this marker in other Studies have been beyond. In the studies, the level of fecal calprotectin in the studies was estimated between 31.6 to $35.9 \mu \mathrm{g} / \mathrm{g}$. Therefore, the evidence obtained indicates the effect of family relationship of the patient with the patient with fecal calprotectin levels. In the present study, we also found that the level of fecal calprotectin is not affected by underlying indicators such as gender, age or BMI (both in patients and their relatives) and therefore these underlying factors will not affect the level of fecal calprotectin.

\section{Conclusion}

As a final conclusion, although fecal calprotectin levels are significantly longer in patients with ulcerative colitis than in healthy controls, the higher level of this marker among firstdegree relatives of patients than healthy individuals also indicate the inherited tendency of changes in this marker in terms of high risk of disease in first-degree relatives of patients. These changes in fecal calprotectin levels will be independent of gender, age, and BMI.

\section{References}

[1] Wallace KL, Zheng LB, Kanazawa Y, Shih DQ. Immunopathology of inflammatory bowel disease. World $\mathrm{J}$ gastroenterol 2014; 20: 6 .

[2] Cho JH. The genetics and immunopathogenesis of inflammatory bowel disease. Nat Rev Immuno 2008; 8: 458.

[3] Ng SC, Shi HY, Hamidi N, Underwood FE, Tang W, Benchimol EI, et al. Worldwide incidence and prevalence of inflammatory bowel disease in the 21 st century: a systematic review of population-based studies. Lancet 2017; 390: 276978.

[4] Norouzinia M, Chaleshi V, Alinaghi S, Beheshti Shirazi SS, Keramatinia A, Nourian M. Evaluation of IL-12A, IL12B, IL$23 \mathrm{~A}$ and IL-27 mRNA expression level genes in peripheral mononuclear cells of inflammatory bowel disease patients in an Iranian population. Gastroenterol Hepatol Bed Bench. 2018; 11: S45-S52.

[5] Norouzinia M, Chaleshi V, Alizadeh AHM, Zali MR. Biomarkers in inflammatory bowel diseases: insight into diagnosis, prognosis and treatment. Gastroenterol Hepatol Bed Bench. 2017; 10: 155-167.

[6] Falvey JD, Hoskin T, Meijer B, Ashcroft A, Walmsley R, Day AS, et al. Disease activity assessment in IBD: clinical indices and biomarkers fail to predict endoscopic remission. Inflammat Bowel Dis 2015; 21: 824-31.

[7] Iskandar HN, Ciorba MA. Biomarkers in inflammatory bowel disease: current practices and recent advances. Trans Res 2012; 159: 313-25.

[8] Foell D, Frosch M, Sorg C, Roth J. Phagocyte-specific calcium-binding S100 proteins as clinical laboratory markers of inflammation. Clin Chim Acta 2004; 344: 37-51.

[9] von Roon AC, Karamountzos L, Purkayastha S, Reese GE, Darzi AW, Teare JP, et al. Diagnostic precision of fecal calprotectin for inflammatory bowel disease and colorectal malignancy. Am J Gastroenterol 2007; 102: 803-13.

[10] Amini AK, Asadzadeh HA, Sorrentino D, Mirzaei A, Shahrokh S, Balaii H, et al. Transmembrane TNF- $\alpha$ Density, but not Soluble TNF- $\alpha$ Level, is Associated with Primary Response to Infliximab in Inflammatory Bowel Disease. Clin Trans Gastroenterol 2017; 8: e117-e.

[11] Aghdaei HA, Kadijani AA, Sorrentino D, Mirzaei A, Shahrokh S, Balaii $\mathrm{H}$, et al. An increased Bax/Bcl-2 ratio in circulating inflammatory cells predicts primary response to infliximab in inflammatory bowel disease patients. United Europ Gastroenterol J 2018:2050640618774637. 
[12] Pardi D, Sandborn W. Predicting relapse in patients with inflammatory bowel disease: what is the role of biomarkers? Gut 2005; 54: 321-2.

[13] Kadijani AA, Javadinia F, Gholamrezaei Z, Mirzaei A, Balaii $\mathrm{H}$, Ghavami SB, et al. Apoptosis markers of circulating leukocytes are associated with the clinical course of inflammatory bowel disease. Gastroenterol Hepatol Bed Bench 2018; 11: S53-8.

[14] Montalto M, Curigliano V, Santoro L, Armuzzi A, Cammarota G, Covino M, Mentella MC, Ancarani F, Manna R, Gasbarrini A, Gasbarrini G. Fecal calprotectin in first-degree relatives of patients with ulcerative colitis. Am J Gastroenterol. 2007 Jan; 102 (1): 132-6. Epub 2006 Nov 13.

[15] Thjodleifsson B, Sigthorsson G, Cariglia N, Reynisdottir I, Gudbjartsson DF, Kristjansson K, Meddings JB, Gudnason V, Wandall JH, Andersen LP, Sherwood R, Kjeld M, Oddsson E, Gudjonsson H, Bjarnason I. Subclinical intestinal inflammation: an inherited abnormality in Crohn's disease relatives? Gastroenterology. 2003 Jun; 124 (7): 1728-37.

[16] Xiang JY, Ouyang Q, Li GD, Xiao NP. Clinical value of fecal calprotectin in determining disease activity of ulcerative colitis. World J Gastroenterol. 2008 Jan 7; 14 (1): 53-7. 